\title{
The Media Mode and Innovation of Animation Culture in the Era of Mobile Internet
} Zong-Hua Tao ${ }^{1}$, Xiao-Cheng Zhou ${ }^{2}$, Zhen-Yan Qin ${ }^{3}$

\author{
${ }^{1}$ Art College, Anhui Sanlian University, Hean Road No. 47, Economic Development Zone,Hefei \\ 230601 \\ ${ }^{2}$ College of Animation,Anhui Xinhua University,Wangjiang Road no. 555, Shushan District, Hefei, \\ 230088 \\ ${ }^{3}$ Art College, Anhui Architecture University, Baohe District No. 856 Jinzhai Road,Hefei 230022
}

KEYWORD: Mobile intelligence; Mobile animation; Cultural inheritance

\begin{abstract}
The Internet animation is a new media ways and means of communication, through between the two culture development and industry trend. Analysis mobile Internet era animation culture for the audience and the market value and role in promoting, by American and Japanese animation culture industry characteristics and industrial mechanism of case analysis, for fusion development and innovation of the Internet animation industry research has a certain theoretical value and practical significance.
\end{abstract}

\section{THE CULTURAL DEVELOPMENT AND INDUSTRY TRENDS OF INTERNET ANIMATION}

The animation industry is considered one of the most promising emerging industries Chinese, twenty-first Century as the most promising sunrise industry, the rapid development of domestic animation, driven around the product, people, the rapid rise of derivatives and several other industrial chain. However, in terms of core animation, Japanese animation throughout the world market, long-term occupation of the market China, animation in the world on the road difficult. With the Chinese economy has entered a new norm, consumption upgrade, expand the cultural consumption market, Chinese animation market has opened a new chapter in the development. Whether the government, the market, for the animation industry more tolerant, facing the development environment is so good, how to become the core content the primary problem in the future development of the animation industry.

In 2015, known as the animation industry development has the "inflection point" and "blast" significance. According to incomplete statistics, in 2015 the animation industry output value has exceeded 1000 million. Behind the domestic animation industry proud of the report, "thrust work Internet" can not be.2015, the Internet and animation industry to accelerate the full range of combination of network animation, mobile phone animation to maintain rapid development.2015 China Mobile mobile phone animation business to maintain a growth rate of more than $30 \%$ hits, hot animation products mainly the animation site are in the hundreds of millions or even billions of times. With the rapid development of animation ontology based on Internet at the same time, also produced many new forms of animation business, promote the development of the real economy.

Cultural industries is not the Ministry of culture for the first time to the animation industry projects carried out to support the work of the. Is worthy of note, the projects to support the animation content limited to promote the socialist core values of animation projects, indicating that the countries more and more attention to output the contents of the animation industry, but also pointed out the development direction for the future of the animation industry.

As we all know, we are now using the Internet technology to understand and construct the world of Kung Fu animation cartoon network, is the world's first animation industry operating platform, to integrate the global animation resources, boost the development of traditional industries. For the purpose of cartoon network through all aspects of the animation industry chain of the record set, sowing that pin awarded four platform, together with customers to build a world-class animation, animation of global distribution through the platform, the rapid sales of children's derivatives, and 
animation copyright authorization to the global derivatives business, the future will be extended from cartoon animation education to raise public sector to achieve a win-win situation, the traditional industry and animation industry. To create animation ecological chain the world's largest trading platform.

Future, cartoon network will at a faster speed of integration of the global animation resources, docking of the real economy construct the world's largest animation industry chain of Internet platform, help the animation industry in resources, business extends infinitely, interoperability, profound changes in global animation ecological chain.

With the implementation of the "The Belt and Road" for the construction of the national strategy, cultural and creative industry development will usher in the peak of the Internet. CCTV Animation "Innovation Summit trend of concern and touted, reflects the economic and social importance of the record industry. While the global animation industry operating platform - cartoon network after the release of the the" Butterfly Effect ", will let the cultural and creative characteristics of the animation industry has become a new engine of economic and social transformation and development.

\section{MOBILE INTERNET ERA OF ANIMATION FOR THE AUDIENCE AND THE MARKET VALUE OF THE ANALYSIS}

The reason why the Internet can change a lot of industry, because of the Internet to the majority of users directly link, change the producers and consumers of the connection. The Internet animation industry also broke the animation producers and consumers of the original connection. The audiences by the television media era of passive choice (TV what animation I'll see what), variable for the age of the Internet initiative choice (what I like choose what), which to the animation producers bring competitive challenges and opportunities. At the same time, a lot of cartoon culture consumers has become content producers, so as to promote the animation industry chain of supply and demand change.

90, 00 in the demand for cultural entertainment and before the user has a very obvious fault, on the one hand, their material life rich enough to live comfortably, and the more effort and pursuit in the spiritual and cultural level; another Internet make the generation of user independent access to the contents of the path more, also let them face the more rich entertainment options. The formation of the fault, so that the two dimensional animation and game entertainment content and become the common pursuit of this generation of young people. They on the Internet and have the same hobby to communicate, sharing, gradually formed a community.

Internet animation development, inseparable from the acquired construct incubated ecological. In this ecosystem, animation enthusiasts can become a professional writer, the ecological chain has a complete chain, cartoon animation, may also transformation for other entertainment content, such as game film and literature, and derived the second element of culture. Tencent many authors are by Tencent animation platform from a cartoon lovers become professional cartoonist, come to the fore through Internet. Here, readers can quickly reflect to the author, content creators and readers between rapid role transformation, create more loved by the readers work, to create popular IP.

When the carrying platform of animation from media into the traditional limitations of mobile Internet now, the audience's reading preferences and habits changed. This had a profound impact on the animation author and the organization, before the animation author can think according to their values, but not now, if you do not follow the fish had no chance of survival, but if blindly pursue fish, will lead to shallow and broad. The animation works become the audience and market values in the industry. But in fact good content is based on the fundamental, "the content is a good platform, the content itself is the operation platform"

Now the Internet and many animation app using social networking platform, video website to cross, the realization of the multimedia, multi angle, multi channels, three-dimensional mode of transmission, so that the animation from the books and television bound can be spread anywhere.2015, the scale of China's Internet users reached 6.68 million, Internet penetration rate was $47.9 \%$, the advent of the Internet era to the spread and development of animation industry provides very convenient conditions. 


\section{THE DEVELOPMENT OF AMERICAN AND JAPANESE ANIMATION CULTURE AND INDUSTRIAL MECHANISM}

With the decline of the traditional media, the development trend of the Internet animation has become the mainstream. Network technology will fully utilize and integrate the cultural resources of the animation industry, to maximize the spread effect, at present the mainstream video platform has own independent broadcast animation resources and the plate.

Animation culture only as the vanguard of the business empire of the Disney, to Disney brings box office income bring more cultural influence subsequent realized. Box office income is the most intuitive, other also includes film subsequent to the issuance of DVD and Blu ray disc, a theme park publicity, and animated characters of authorization and peripheral products sale. With animation works to build brand image and subsequent industrial chain as a downstream capital income, the industry model of this type in the United States market capitalism was quite a success.

The Disney is the most representative of the United States in the animation industry, from the earliest animation production, issue now involves broadcasting, animation, film and entertainment industry in almost all cultural fields, has become an important channel of American foreign cultural output per year. Disney produced animation works can set off a wave of wave of viewing in the world after the release of its surrounding products and Disney park also brought huge revenues for the Disney company, not only that, according to the development of animation products out of the hotel, books and other business activities also showed an increasing trend. Disney produced from the earliest animation company has gradually become an the world's second largest entertainment industry empire.

In addition to the animation industry in the United States, Japan's animation industry has become Japan's economic pillars, the animation industry in Japan's annual output value reached 230 trillion yuan, more than $60 \%$ of the global animation works are from Japan, the animation industry in Japan's economic structure accounted for more than $10 \%$, has become the third biggest economy industry in Japan.

Be quite different Japanese animation industry development of the animation industry and the United States, Japan's animation industry chain is established on top of huge comic industry, although there are a variety of large and small scale companies, but such us animation industry in Disney has no monopoly position. That is to say the Japanese animation industry is a national industry, they have powerful and rich comic cartoon system complex, after years of development, has formed its own unique cultural heritage and manga comics.

Cartoon animation into the link, reduce the number of animation when the high capital investment, and original comic fan base, also need not worry too much about the ratings, but do not deviate from the market risk into the bottleneck, greatly reduces the risk of Japan's animation unit undertakes. Then IP authorization and derivative products sales have become the most profitable part of the Japanese animation industry. The depth of the development of successful animation products, animation industry chain formed a healthy benign recycling for the development of new animation products two, good convergence of the industrial chain to form a virtuous cycle of progressive mode benefit. In the whole industry chain, all aspects of the units, departments have detailed division of labor, comic studio, animation studio, copyright agency, printing and publishing enterprises, distribution enterprises of books, magazines, television, animation derivatives Raw materials production and sales channels and so on have formed a clear boundaries of the cooperation mechanism.

\section{INTEGRATION DEVELOPMENT AND INNOVATION OF THE INTERNET ANIMATION INDUSTRY}

Internet expands the route of transmission of the animation. One is completely break the traditional animation broadcast channels of the scarcity of our. Whether it is television or movies, traditional animation broadcast channels are called scarce resources. And the emergence of many new media of the Internet era, equivalent to star a never stop broadcast channel, build the piece of cinema, a never. Second, change the one-way communication mode, for animation viewing experience increases the interactive and entertaining. Third, expand the spread of the audience group. 
The Internet has changed the way of creative animation. Production from the scale of moving in the direction of customization. Traditional animation is industrial civilization under the large-scale production of cultural products, I do what you see; and in the Internet age, the production into you see what I do, based on data analysis of works began to emerge. The second is the creation threshold greatly reduced. Originally only a few animation companies can animation creative production, now on the market has appeared in large numbers by the grassroots, small studio and other folk strength according to their own preferences, for all segments of the market, the creation of a large number of small cost, short regulation animation content.

In investment financing mode change and marketing profitable way change of environment, the development of animation industry will have new development and change of the pattern, one is the original animation content creation made an important breakthrough, boost the confidence of the industry development; the second is to IP to lead the industry development has become an important trend in the development of the animation industry; the third is the capital of animation industry, more attention and investment; the fourth is the Internet for the development of animation industry in the wings; fifth anime convention become the highlight of the animation industry to promote consumption; six is animation go space is more and more broad.

In order to further promote the development of animation industry, but also necessary measures for development and innovation, one is to actively guide the creation orientation; the second is to promote the animation industry to upgrade the quality; third is to actively promote cultural consumption; four is to promote the combination of animation and technology; the fifth is to continue to promote the development of China's animation to go out.

Chinese animation industry is entering to the Internet as the core, cross shape, cross media, cross industry integration and development of the new era. Chinese Research Institute released the report pointed out that the integration of the development of the Internet animation industry will make the future pattern of animation industry has undergone fundamental changes.

\section{CONCLUSION}

A few years ago in the late of the economy development of cultural and creative industries in the period of strategic opportunities, post crisis under the background of industrialization, and puts forward the development of cultural and creative industries to promote industrial restructuring, and accelerate the development of modern manufacturing industry and modern service industry. Under the background of the globalization of the world economy and the background of China's economic transformation, the transformation of creative design industry under the background of cultural science and technology integration is proposed.

Visible culture and science and technology are becoming increasingly integrated, complementary, culture and technology integration is not a simple addition, but the organic integration. Transformation of creative design industry is in the context of the rapid development of information and network technology, the design industry and other cultural, technological and industrial integration to form a new industry.

"Internet plus" is to promote the birth of more Internet start-ups, and without the cost of manpower, material and financial resources to the research and implementation of industry transformation. It can be said that every social and commercial stage has a normal as well as the development trend of "Internet plus" before the normal background is the need to upgrade the tens of millions of enterprises.

In the future will be a big data driven era. The development of the Internet has changed the pattern of the Chinese animation market, the rapid development of the Internet, as well as the animation industry, it also brings some new thinking and industry requirements. Internet plus let us in the animation more perfectly, Internet plus make animation more vertical, more accurate to find the love of their people, everyone is full of feelings and dreams to reality more together. Seek development of animation industry in the era of big data under the Internet plus platform, which is an important stage of animation creation, big data marketing, authorized the whole field of a development and application, is not a matter of expediency, is the only way which must be passed. 


\section{ITEM NUMBERS:}

[1] The provincial quality project (professional comprehensive reform pilot project) project Animation (project number: 2014zy0801);

[2] The quality of the project (professional comprehensive reform pilot project) - animation project (project number: 13zlgc004);

[3] Provincial-level humanities and Social Sciences (key), Wanjiang City Belt of animation industry cluster development mode reform research (project number: SK2015A631);

[4] provincial revitalization plan project - animation professional structure optimization adjustment and professional transformation (project number: 2015zytz073);

[5] The scientific research fund project platform -- Anhui folk art of the digital performance (project number: 2015005);

[6] Provincial college students innovation and entrepreneurship training program (innovation training program) - based on interactive technology of infant preschool education app development and application (project number: 201510959043);

[7]University Quality Engineering (school enterprise cooperation practice education base project - Anhui Sanlian College Union Bank Information Technology (Shanghai) Co., Ltd. digital art education practice base (project number: 13zlgc016);

[8] The University Research Fund platform project the civilian run colleges and Universities -production cooperation "public digital art design practice research (project number: 2015006);

[9] The Provincial Quality Engineering (General Teaching Research) project - the new undergraduate colleges and universities multimedia teaching quality guarantee research -- take the Anhui Institute as an example

[10] Project number: 2014jyxm420;

[11] Provincial humanities and Social Science (key) project - Anhui local original animation industry cluster growth research (project number: SK2016A0342);

[12] Provincial humanities and Social Science (key) project - folk art "digital" preservation of the research (project number: SK2015A0351);

\section{REFERENCES:}

[1] Li Xiangyu. Cartoon brand building under the new media environment [D]. Shandong University, 2013

[2] $\mathrm{Wu}$ Yi. The interactive relationship between mobile media and animation industry [J]. news lovers, 2014,05:72-74. 